\title{
Membranoproliferative Glomerulonephritis and Inflammatory Pseudotumour of the Spleen
}

\author{
U. Hadimeri ${ }^{a} \quad$ P. Hultman ${ }^{\text {c }} \quad$ R. Larsson ${ }^{d} \quad$ S. Melander ${ }^{d} \quad$ J. Mölne \\ H. Hadimeri ${ }^{b}$ \\ Departments of ${ }^{a}$ Radiology and ${ }^{b}$ Nephrology, Kärnsjukhuset, Skövde, ${ }^{c}$ Division of \\ Molecular and Immunological Pathology, and ${ }^{\mathrm{d}}$ Department of Nephrology, Linköping \\ University, Linköping, and ${ }^{\mathrm{e}}$ Department of Pathology, Sahlgrenska University \\ Hospital/Campus Sahlgrenska, Göteborg, Sweden
}

\section{Key Words}

Inflammatory pseudotumour $\cdot$ Spleen $\cdot$ Membranoproliferative glomerulonephritis

\begin{abstract}
Inflammatory pseudotumour is a rare condition that can affect various organs. The clinical and histologic appearance of the pseudotumour may mimic haematological, lymphoproliferative, paraneoplastic or malignant processes. A previously healthy 39-year-old man presented with nephrotic syndrome. He had a history of headaches, nausea and swollen ankles. Computed tomography of the abdomen revealed a $6-\mathrm{cm}$ mass in the spleen. Following a renal biopsy, a diagnosis of membranoproliferative glomerulonephritis (MPGN) type I was made. Splenectomy was performed and the examination revealed a mixed population of lymphocytes with predominantly T-cells, B-cells and lymphoplasmacytoid cells. Immunostaining confirmed that the small cells were mostly $\mathrm{T}$-cells positive for all T-cell markers including $C D 2, C D 3, C D 4, C D 5, C D 7$ and $C D 8$. A diagnosis of inflammatory pseudotumour was established. The removal of the spleen was followed by remission of glomerulonephritis, but it was complicated by a subphrenic abscess and pneumonia. This association between an inflammatory pseudotumour of the spleen and MPGN has not been previously described. Abnormal immune response due to the inflammation leading to secondary glomerulonephritis might be the main pathogenic mechanism.
\end{abstract}




\section{Introduction}

Inflammatory pseudotumour is a rare condition that can affect various organs, e.g. the lungs and pancreas $[1,2]$. Pseudotumours in the lymphoreticular organs, such as the spleen, have been described previously by several authors. The clinical and histological appearance of a pseudotumour may mimic haematological, lymphoproliferative, paraneoplastic or malignant processes. The cause of inflammatory pseudotumour is usually unknown [3-7]. Membranoproliferative glomerulonephritis (MPGN) or mesangiocapillary glomerulonephritis is characterized by deposition in the glomerular mesangium, thickening of the basement membrane and complement activation. These alterations lead to glomerular damage. MPGN is divided into primary (idiopathic) and secondary types, which are more common. There are also at least 2 subtypes of this nephropathy (types 1 and 2). MPGN accounts for less than $5 \%$ of all glomerulonephritis forms. The clinical picture is similar to that of other glomerulopathies and often presents with a nephrotic syndrome [8]. The presence of portosystemic shunting and a defect in the clearance of soluble immune complexes by the hepatic Kupffer cells, resulting in deposition of immune complexes in glomeruli in the pathogenesis of secondary MPGN, have been suggested by Soma et al. [9]. We report a case of this unusual form of glomerulonephritis associated with a pseudotumour located in the spleen.

\section{Case Report}

A previously healthy 39-year-old Iranian man was admitted to the Department of Internal Medicine with nephrotic syndrome. He had a history of upper respiratory tract infection for the past 2 weeks, headaches, nausea and swollen ankles.

On admission to the hospital, he had peripheral oedema, no abdominal symptoms, and his blood pressure was $170 / 120 \mathrm{~mm}$ Hg. Laboratory investigations (reference values): haemoglobin $125(131-163) \mathrm{g} / \mathrm{l}$; white blood cell count $10.3(4-9) \times 10^{9} / \mathrm{l}$, platelets 356 $(140-350) \times 10^{9} / \mathrm{l}$, C-reactive protein $11(<5) \mathrm{mg} / \mathrm{l}$; serum creatinine $(\mathrm{Cr}) 103(50-115)$ $\mu \mathrm{mol} / \mathrm{l}$, serum albumin 22 (36-48) g/l, 24-hour urinary protein excretion $4.92 \mathrm{~g} / \mathrm{l}$. Microscopic examination of urine (power field $\times 400$ ) showed 8-10 erythrocytes, 12-15 leucocytes, 1-3 hyaline casts/10 fields and 1-2 granular casts/10 fields. A chest X-ray revealed nothing abnormal.

Ultrasonography of the abdomen showed no evidence of postrenal obstruction, but it revealed a circumscribed hypoechoic lesion in the spleen. Computed tomography (CT) of the abdomen using intravenous contrast revealed a 6-cm mass in the spleen, which had a thin contrast uptake at the periphery of the lesion in the arterial phase. In the late venous phase, the tumour enhanced the contrast almost completely and was isoattenuating (fig. 1). Treatment with captopril and furosemide was instituted (fig. 2).

After 5 days the patient was transferred to the university hospital. Laboratory investigations, Cr 185 (50-115) umol/l, 24-hour urinary protein excretion $9 \mathrm{~g} / \mathrm{l}$; antineutrophil cytoplasmic antibodies as well as antinuclear antibodies were negative. C3, C4 and C3d were within the normal range with a slight elevation of C3d in comparison with C3, suggesting complement activation. A test for anti-glomerular basement membrane (anti-GBM) was slightly positive. Serology for Echinococcus infection and hepatitis B and C were negative. Bone marrow investigation revealed no pathology. On the weak suspicion of anti-GBM, nephritis therapy with plasmapheresis every second day and $15 \mathrm{mg}$ of prednisolone daily was initiated. 
Hadimeri et al.: Membranoproliferative Glomerulonephritis and Inflammatory Pseudotumour of the Spleen

A renal biopsy was performed 10 days after the initial hospital admission. A diagnosis of MPGN type I was obtained (fig. 3) and the plasmapheresis procedure was discontinued after 2 treatment sessions. The prednisolone medication dosage was then also reduced.

One month later, the patient underwent a fine-needle aspiration biopsy of the spleen, which showed no lymphocytic atypia but a slight increase in immature plasma cells. A few atypically large histiocytic cells with large nucleoli were observed as well as an increased number of eosinophilic granulocytes. The possibility of Hodgkin's disease was raised. The clinical status of the patient 2 months later was stable without peripheral oedema; his blood pressure was 135/85 mm Hg.

Three months later, a splenectomy was performed and the histopathological examination revealed a spindle cell component in the background and a clear appearance of collagen stromal formation. In this formation, there were many lymphocyte-like cells that did not appear to form follicles. Immunophenotyping confirmed that the spindle cell component was positive for CD68 and vimentin, and negative for smooth cell antigen and various cytokines. The lymphocyte-like cells showed a high level of positivity for T-cell markers such as CD3, while the positivity for B-cell markers (CD20) was within normal limits. Staining for kappa and lambda was the same as in the adjacent normal splenic tissue. The extratumoural tissue revealed no pathology. The diagnosis of inflammatory pseudotumour was established. A liver biopsy revealed normal tissue. A thorough oncological evaluation with CT of the thorax and brain, and a complete endocrine tumour examination revealed no abnormalities.

The removal of the spleen was complicated by a subphrenic abscess and pneumonia, which was treated successfully with pleural drainage and antibiotics. Six months later, the patient was followed up on an outpatient basis where he was considered to appear to be well. Upon clinical investigation, the patient had normal auscultation of the heart and lungs, no abdominal symptoms and did not display any oedema; his blood pressure was 160/110 $\mathrm{mm} \mathrm{Hg}$. Laboratory investigations revealed: haemoglobin $122 \mathrm{~g} / \mathrm{l}$; creatinine clearance 77 $\mathrm{ml} / \mathrm{min}$; 24-hour protein excretion $0.7 \mathrm{~g} / \mathrm{l}$. Serum protein electrophoresis was normal without hypoalbuminaemia or elevation of M-protein. Microscopic examination of the urine showed 30-35 erythrocytes and 4-6 leucocytes but no casts. Follow-up renal biopsy was performed but, unfortunately, contained no glomeruli although tubuli and interstitium were unremarkable. The prednisolone treatment was stopped 11 months after initiation. Examination 5 years later revealed the following values: urinary protein excretion below 0.5 $\mathrm{g} / \mathrm{l}, \mathrm{Cr} 116 \mu \mathrm{mol} / \mathrm{l}$, and blood pressure 135/85 mm Hg.

\section{Discussion}

MPGN secondary to paraneoplastic processes, e.g. hydatidiform mole, has previously been reported in the literature [10]. In previous publications of inflammatory pseudotumour, no renal symptoms were registered except for 2 cases where renal malignancies were associated with an inflammatory pseudotumour [5].

In our case, the absence of positive serology for intercurrent infections mainly rules out bacterial and viral causes of MPGN, although the initial respiratory tract infection may have triggered the process. Prior systemic bacterial infections in the pathogenesis of inflammatory pseudotumour have been reported by others investigators [10,11]. Chromosomal aberrations may be of importance, although no genetic linkage investigation was performed in our case [4].

The results of the radiological and bone marrow investigation procedures excluded malignancy as a reason for cause of the secondary glomerulonephritis. The isoattenuation of 
Hadimeri et al.: Membranoproliferative Glomerulonephritis and Inflammatory Pseudotumour of the Spleen

the tumour may, however, cause diagnostic difficulties in the absence of necrotic tissue. The histological appearance and the immunophenotyping are consistent with previous reports of similar types of tumours [10].

The remission of glomerulonephritis after splenectomy in our case suggests a causal relationship. Although conservative treatment with steroids is possible, surgical removal of the pseudotumour is probably the best diagnostic and therapeutic procedure [6]. In the present case, the modest proteinuria as well as erythrocyturia and leucocyturia may indicate residual renal damage. However, the long-term consequences of these findings are uncertain. The prognosis is usually favourable, with partial or complete recovery of renal function [10].

The mechanisms leading to the recovery of renal function in this case are unclear. However, we speculate that the inflammatory pseudotumour was caused by an unknown infectious agent, as has been shown in many other cases $[11,12]$. Treatment of pseudotumours is often the removal of the tumour and/or treatment with immunosuppressants, usually steroids. In our case the tumour was removed and the patient was prescribed steroids for a total of 11 months. The patient had biopsy-proven MPGN, which is often caused by chronic infections, most often hepatitis B or C [13]. We think that both the inflammatory pseudotumour and the MPGN may have been caused by an unknown infectious agent, probably resulting in his respiratory tract infection. Removal of the tumour and immunosuppression reduced the patient's immune responses, and immune complex formation in the kidney then gradually disappeared and kidney function improved.

An alternative explanation is that the pseudotumour produced some antigen, possibly a cytokine, as the process is dominated by T-cells and macrophages. There is at least 1 article reporting IL-1 production from an inflammatory pseudotumour [14].

We believe this to be the first reported case of inflammatory pseudotumour in the spleen associated with MPGN. Abnormal immune response owing to the inflammation and leading to secondary glomerulonephritis might be the main pathogenic mechanism.

\section{References}

1 Hadimeri U, Hadimeri H, Resjö M: Inflammatory pseudotumor of the lung. A case report. Pediatr Radiol 1993;23:624-625.

2 Wiesner W, Kocher T, Beglinger C, Harder F, Steinbrich W: Pseudotumor of the pancreatic head associated with idiopathic retroperitoneal fibrosis. Dig Surg 2001;18:418-421.

-3 Sheahan K, Wolf BC, Neiman RS: Inflammatory pseudotumor of the spleen. A clinicopathologic study of three cases. Hum Pathol 1996;19:1024-1029.

-4 Griffin CA, Hawkins AL, Dvorak C, Henle C, Ellingham T, Perlman EJ: Recurrent involvement of 2p23 in inflammatory myofibroblastic tumors. Cancer Res 1999;59:2776-2780.

-5 Neuhauser TS, Derringer DA, Thomsson LD, Fanburg-Smith JC, Aguilera NS, Andriko J, Chu WS, Abbondanzo SL: Splenic inflammatory myofibroblastic tumor (inflammatory pseudotumor). A clinicopathologic and immunophenotypic study of 12 cases. Arch Pathol Lab Med 2001;125:379-385.

6 McHenry CR, Percy-Gall HB, Mardini G, Chung-Park M: Inflammatory pseudotumor of the spleen: a rare entity that may mimic hematopoietic malignancy. Am Surg 1995;61:1067-1071.

7 Dehner LP: The enigmatic inflammatory pseudotumors: the current state of our understanding, or misunderstanding (editorial). J Pathol 2000;192:277-279.

8 Rennke HG: Secondary membranoproliferative glomerulonephritis. Kidney Int 1995;47:643-656.

-9 Soma J, Saito T, Sato H, Ootaka T, Abe K: Membranoproliferative glomerulonephritis induced by portosystemic shunt surgery for non-cirrhotic portal hypertension. Clin Nephrol 1997;48:274-281.

10 Han BG, Kim MH, Karl EH, Hong SW, Choi SO: A case of membranoproliferative glomerulonephritis associated with a hydatidiform mole. Yonsei Med J 2000;41:407-410.

11 Lewis JT, Gaffrey RL, Casey MB, Farrel MA, Morice WG, Macon WR: Inflammatory pseudotumor of the spleen associated with a clonal Epstein-Barr virus genome. Case report and review of the literature. Am J Clin Pathol 2003;120:56-61. 


\section{Case Reports in Oncology}

\begin{tabular}{l|l}
\hline Case Rep Oncol 2013;6:84-89 \\
\hline DOI: $\underline{10.1159 / 000347229}$ & $\begin{array}{l}\text { ○ 2013 S. Karger AG, Basel } \\
\text { www.karger.com/cro }\end{array}$ \\
\hline
\end{tabular}

Hadimeri et al:: Membranoproliferative Glomerulonephritis and Inflammatory Pseudotumour of the Spleen

12 Wood C, Nickoloff BJ, Todes-Taylor NR: Pseudotumor resulting from atypical mycobacterial infection: a 'histoid' variety of Mycobacterium avium-intracellulare complex infection. Am J Clin Pathol 1985;83:524527.

-13 Haffner D, Schindera F, Aschoff A, Matthias S, Waldherr R, Scharer K: The clinical spectrum of shunt nephritis. Nephrol Dial Transplant 1997;12:1143-1148.

14 Hytiroglou P, Brandwein MS, Stauchen JA, Mirante JP, Urken ML, Biller HF: Inflammatory pseudotumor of the parapharyngeal space: case report and review of the literature. Head Neck 1992;14:230-234.

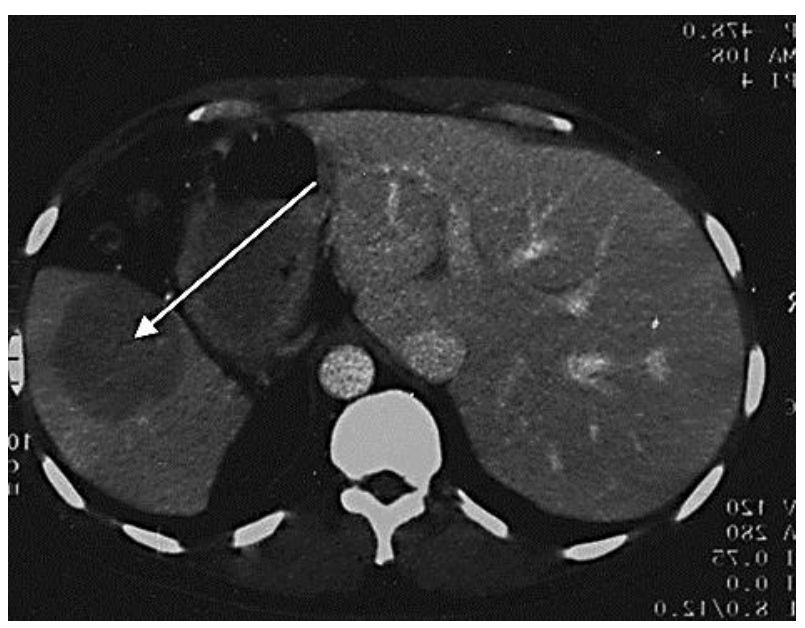

Fig. 1. Inflammatory pseudotumour located in the spleen.

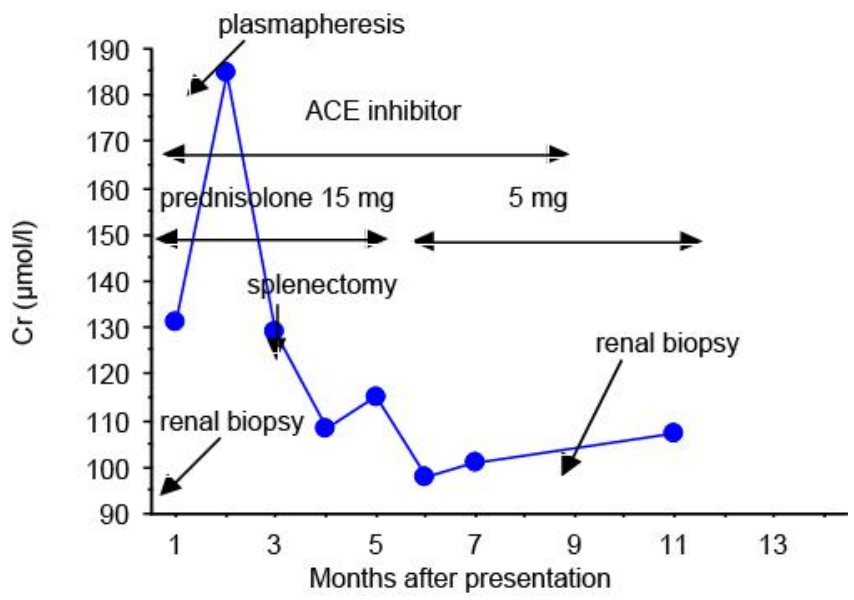

Fig. 2. Clinical course of MPGN associated with pseudotumour in the spleen. 


\section{Case Reports in Oncology}

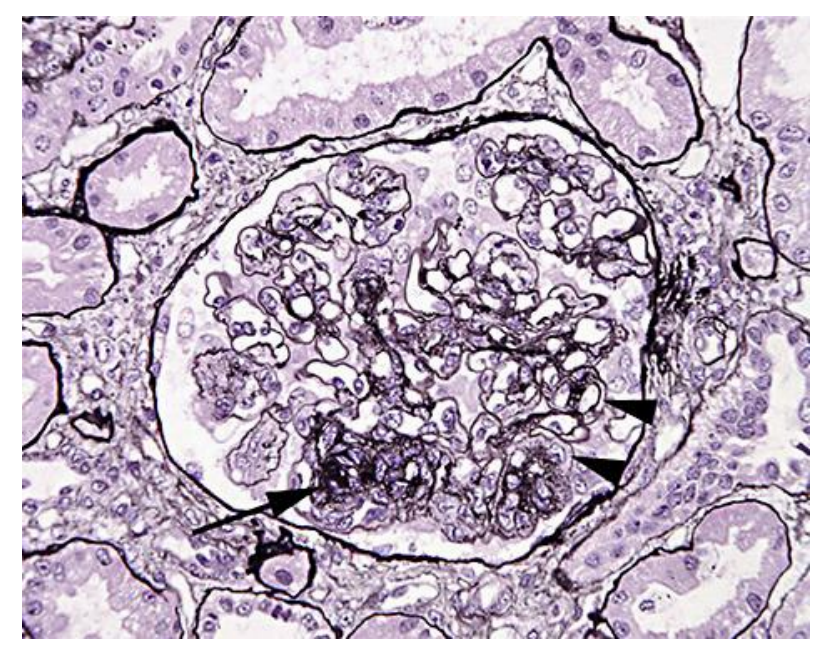

Fig. 3. PAS-silver stain of a representative glomerulus. The renal biopsy contained cortex with 14 glomeruli with a pronounced accentuation of the lobules. There was a mesangial matrix and cell increase (arrow), and in some capillaries double contours can be seen (arrowheads) forming a membranoproliferative pattern. No crescents were observed. Immunofluorescence (not shown) showed predominantly membranous, granular deposits of $\mathrm{C} 3 \mathrm{c}$ and $\operatorname{IgG}$ and lower amounts of $\operatorname{IgM}, \operatorname{IgA}$ and C1q. Electron microscopy (not shown) demonstrated modest but distinct electron-dense deposits in the subendothelial zone and scattered subepithelial deposits. There was a mesangial cell proliferation and focal interpositioning in the thickened capillary walls. The final morphological diagnosis was MPGN type I. 